\title{
Improvement of the Mechanical Properties of Hibiscus Esculentus (Okra) Fiber Reinforced Polymer Composite
}

\author{
D. I. Chukwuma ${ }^{1}$, E. N. Ikezue ${ }^{1}$, E. O. Onu ${ }^{1,2}$ and J. O. Ezeugo ${ }^{1, *}$ \\ ${ }^{1}$ Department of Chemical Engineering, Chukwumeka Odumegwu Ojukwu University, \\ Anambra State, Nigeria \\ ${ }^{2}$ Department of Chemical Engineering, Nnamdi Azikwe University, Awka, Nigeria \\ *Corresponding author's e-mail: jn.ezeugo@ coou.edu.ng
}

\begin{abstract}
Natural fiber and their composites are the emerging trends in material science. They are speedily gaining grounds in the replacement of synthetic reinforcements. This is due to their low density, high specific mechanical strength, ultimate availability and disposability and less processing requirements. Most plant based fibers have become centers of research. This work is based on Okra fiber. Okra fiber was used as reinforcement in vinyl ester polymer matrix. Okra fiber was chemically treated using $\mathrm{NaOH}$ to clean fiber surface, modify the surface to increase the surface roughness and in general enhance bond strength between fiber and matrix. Reinforcement of the matrix using Okra fiber increases mechanical properties of the composite. But for optimal result, certain parameters were considered and varied. The two parameters considered were: fiber length, and proportion or volume fraction. Different variations of fiber length considered were: $10 \mathrm{~mm}, 30 \mathrm{~mm}$ and $50 \mathrm{~mm}$ while the different fiber volume fractions considered are $10 \%, 30 \%$ and $50 \%$. This work has analyzed how these parameters can be best combined for optimum values of tensile properties of the composite. The tensile strength of composite was highest at fiber length of $50 \mathrm{~mm}$ and volume fraction of $10 \%$ at ultimate tensile strength of $214 \mathrm{MPa}$.
\end{abstract}

\section{Introduction}

We find composites everywhere around us. Composite is a material system Received: August 4, 2019; Accepted: September 9, 2019

Keywords and phrases: Okra fiber, vinyl ester, tensile strength, sodium hydroxide $(\mathrm{NaOH})$.

Copyright (ㅇ 2019 J. O. Ezeugo et al. This is an open access article distributed under the Creative Commons Attribution License, which permits unrestricted use, distribution, and reproduction in any medium, provided the original work is properly cited. 
composed of two or more physically distinct phases whose combination produces synergistic effect and aggregate properties that are different from those of its constituents. Many materials existing in nature, such as bones in the human body, wood and bamboo in the forest, derive their superb mechanical properties by combining two or more macroscopic components or constituents.

A composite in this respect is a compound formed between a polymer and a fibrous material. These polymer composite products have good mechanical properties per unit weight, are durable and their technologies allow the manufacture of complex and rare shapes. In recent times natural fibers have been used as reinforcement for polymer composite creation. Natural fibers are derived from plants, animals and mineral sources. Plant fibers are widely used for composite fabrication. The properties of these fibers depend on the nature of the plant, locality in which it is grown and age (Joseph et al. [3], Khandal et al. [4] and Kuchinda et al. [5]). Natural fibers are fast displacing glass and other industrial fibers due to its low specificity, high specific strength and stiffness. It has renewability source advantage over glass fiber as well as cost effectiveness. Furthermore, reduction of wear of tooling, healthier working condition and no skin irritation coupled with thermal recycling and acoustic insulating properties are inevitable.

Nevertheless, to fabricate a polymer composite with good mechanical properties, control parameters; fiber length and volume fraction of reinforcement material (natural fiber) play significant role (Mohanty et al. [8]). In this work the chosen fiber length and volume fraction are $10 \mathrm{~mm}, 30 \mathrm{~mm}, 50 \mathrm{~mm}$, and $10 \%, 30 \% 50 \%$, respectively.

Also previous studies have proved the importance of chemically treating the plant fiber that will be used as reinforcement in composite fabrication. According to the work of Xing et al. [2], proper chemical treatment will reduce moisture sensitivity, biological decay and optimize fiber matrix interface thus enabling perfect bonding strength.

Mattoso et al. [6], Martins and Joekes [7] also opined that by treating the fibers with suitable chemicals, the reinforcing efficiency of the fibers in the composite and the interfacial adhesion between fibers and most polymers is established.

Ray and Sarkar [9] investigated the changes occurring in jute fibers after $5 \% \mathrm{NaOH}$ solution treatment was done. He ascertained that the tenacity and modulus of fiber improved by $45 \%$ and $79 \%$, respectively. 
In this work, the Okra fiber used as reinforcement was treated with $\mathrm{NaOH}$.

Natural fiber has become a huge attraction for researchers as it can be used to create composite raw materials for the manufacturing of products in a wide range of industries such as building and construction, automotive, electrical, domestic items etc.

A possible route for broadening the number of species from which plant fibers are extracted to be employed for massive composite creation would be turning to local fibers. One of these locally available plants is the Okra Plant.

\section{Okra Fiber}

Okra fiber is a natural plant fiber extracted from the bark of the Okra plant, a plant of the Malvaceae family, known botanically as Hibiscus esculentus. They are not dissimilar chemically from plants such as pineapple, whose fibers found some use as reinforcement in composites. The color of Okra fiber is quite variable, from whitish to yellowish, depending on the action of UV radiation, a fact which generates some concern on the effect of solar exposure on them [1].

\section{Materials and Method}

\subsection{Sample collection}

The Okra stem was harvested in an Okra farm located in Umuoma, a village in Uli, Latitude 5.7833 and Longitude 6.8667, Ihiala Local Government Area of Anambra State.

\subsection{Methodology}

For the purpose of analyzing and optimization of the tensile test results of fabricated composite samples, response surface methodology (RSM) was employed. A second order quadratic model is used:

$$
\hat{Y}=a_{0}+a_{1} X_{1}+a_{2} X_{2}+a_{3} X_{1} X_{2}+a_{4} X_{1}^{2}+a_{5} X_{2}^{2}+E
$$

where:

$\hat{Y}=$ Response, $X_{1}=$ fiber length (fl) $(\mathrm{mm}), X_{2}=$ fiber volume fraction (vf) $(\%), a_{0}$, $a_{1}, a_{2}, a_{3}, a_{4}$ and $a_{5}$ are constants, and $E=$ error observed in the response. 


\subsection{Reagents}

The major chemicals used are $\mathrm{NaOH}$ for chemical treatment of fiber and vinyl ester as polymer matrix base for the composite.

\subsection{Sample preparation}

The central part of the Okra stem was removed and kept under water to allow microbial degradation. Within 15-25 days, the stems degraded appreciably to allow fiber extraction. The fibers were isolated from the degraded stems by washing with detergent, rinsed in clean water and allowed to dry under the sun, then kept in moisture proof container. Afterwards fiber was chopped into lengths of $10 \mathrm{~mm}, 30 \mathrm{~mm}$ and $50 \mathrm{~mm}$.

\subsection{Chemical treatment of fiber}

The Okra fibers are chemically treated with sodium hydroxide $(\mathrm{NaOH})$. The fibers were dipped into $2 \%$ solution of $\mathrm{NaOH}$, for an hour under constant stirring and allowed for $24 \mathrm{hrs}$ at room temperature and then dried in open air for 6-7 days.

\subsection{Mould preparation fiber laying and impregnation}

The mould is waxed for easy removal of composite. By simple hand lay-up technique, the fiber is soaked into the vinyl ester resin in the mould for different volume fractions: $10 \%, 30 \%$ and $50 \%$. Composite was allowed to cure.

\subsection{Sample characterization}

The composite samples were separated accordingly to have nine (9) samples with fiber proportion as follows:

Table 1. Sample characterization.

\begin{tabular}{|l|l|l|l|l|l|l|l|l|l|}
\hline Fiber length (mm) & 10 & 10 & 10 & 30 & 30 & 30 & 50 & 50 & 50 \\
\hline Volume Fraction (\%) & 10 & 30 & 50 & 10 & 30 & 50 & 10 & 30 & 50 \\
\hline
\end{tabular}

\subsection{Tensile test}

The tensile properties were ascertained using a Hounsfield Monsanto Universal Tensometer Machine at a constant rate of traverse of the moving grip of $5 \mathrm{~mm} \mathrm{~min}^{-1}$ for randomly oriented fiber composites (ASTMD638-99) and 20mm/min for oriented fiber composites (ASTM 05083). The test specimens were rectangular in shape with dimensions $(100 \times 19 \times 3.2) \mathrm{mm}$ for randomly oriented fiber composites. 


\section{Results and Discussion}

The results of the tensile test on the Okra fiber reinforced polymer composite are as shown on the table.

Table 2. Okra tensile test analysis.

\begin{tabular}{|l|l|l|l|l|l|}
\hline $\begin{array}{l}\text { Fiber Length } \\
(\mathbf{m m})\end{array}$ & $\begin{array}{l}\text { Volume } \\
\text { Fraction (\%) }\end{array}$ & $\begin{array}{l}\text { Tensile st. } \\
(\mathbf{M P a})\end{array}$ & $\begin{array}{l}\text { Modulus } \\
(\mathbf{M P a})\end{array}$ & Toughness & $\begin{array}{l}\text { Ultimate el. } \\
(\mathbf{m m})\end{array}$ \\
\hline 10 & 10 & 32.89 & 2.4024 & 0.4118 & 1.88 \\
\hline 10 & 30 & 74.01 & 6.6654 & 0.5399 & 1.41 \\
\hline 10 & 50 & 143.91 & 11.0936 & 1.4782 & 1.88 \\
\hline 30 & 10 & 143.9 & 12.5941 & 1.7176 & 2.50 \\
\hline 30 & 30 & 143.91 & 10.7110 & 0.7075 & 0.94 \\
\hline 30 & 50 & 197.37 & 8.5054 & 4.6616 & 4.38 \\
\hline 50 & 10 & 209.7 & 17.140 & 3.0489 & 2.81 \\
\hline 50 & 30 & 193.26 & 6.5285 & 1.7213 & 2.18 \\
\hline 50 & 50 & 98.68 & 5.1034 & 0.5167 & 1.41 \\
\hline
\end{tabular}

Table 3. Response surface model table for tensile strength analysis.

\begin{tabular}{|l|l|l|l|l|l|}
\hline Variables & Coefficients & Std. Error & t-stat & P-value & F-stat \\
\hline Constant & -119.8828 & 63.1746 & -1.8976 & 0.154 & SSE=2583.9 \\
\hline Fiber Length (mm) & 11.7013 & 3.3556 & 3.4871 & 0.0398 & DFE=3 \\
\hline Volume Frac. (\%) & 4.5066 & 3.3556 & 1.3430 & 0.2718 & DFR=5 \\
\hline Fiber Length*Vol. Frac. & -0.1388 & 0.0367 & -3.7829 & 0.0324 & SSR=25927 \\
\hline Fiber Length^2 & -0.0908 & 0.0519 & -1.7501 & 0.1784 & F=6.0203 \\
\hline Volume Frac.^2 & 0.0017 & 0.0519 & 0.0328 & 0.9759 & $\begin{array}{l}\text { P-val } \\
=0.085205\end{array}$ \\
\hline & & & & & \\
\hline
\end{tabular}

Table 4. Analysis of variance for tensile strength

\begin{tabular}{|llllll|}
\hline Source & Sum Sq. & d. $f$ & Mean Sq. & F & Prob $>$ F \\
\hline X1 & 13124 & 2 & 6562 & 1.76 & 0.2829 \\
X2 & 477.4 & 2 & 238.72 & 0.06 & 0.9389 \\
Brror & 14909.4 & 4 & 3727.34 & & \\
Total & 28510.8 & 8 & & & \\
& & & & & \\
& & & & & \\
\end{tabular}




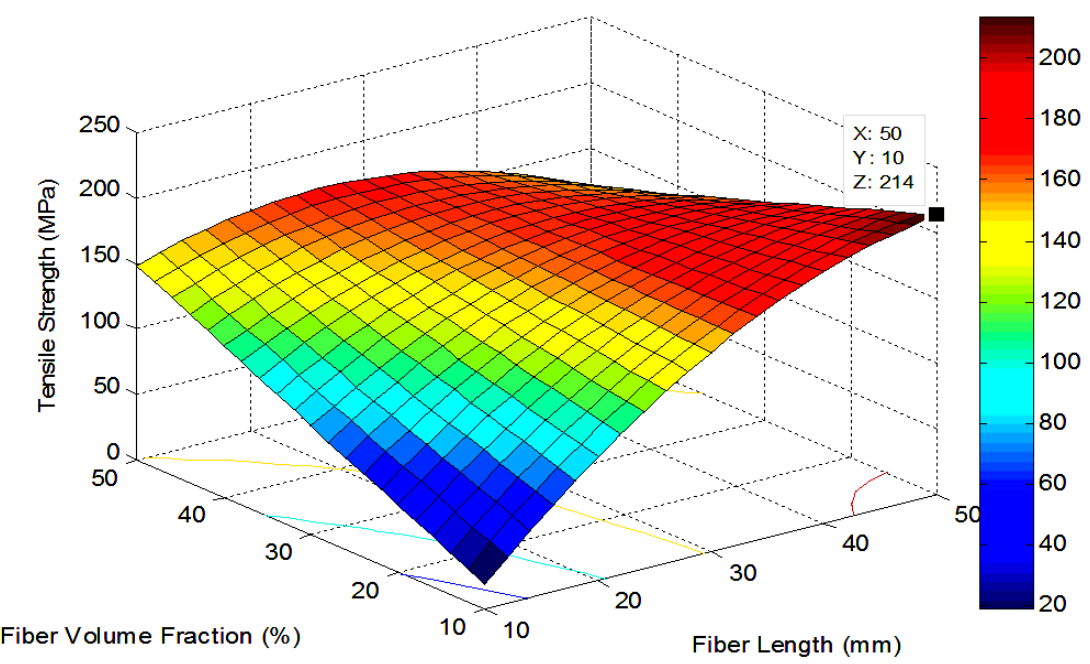

Figure 1. Surface plot and analysis of variance for tensile strength.

Table 5. Response surface model table for modulus of elasticity analysis.

\begin{tabular}{|l|l|l|l|l|l|}
\hline Variables & Coefficients & Std. Error & t-stat & P-value & F-stat \\
\hline Constant & -4.4752 & 4.2152 & -1.0617 & 0.3663 & SSE $=11.503$ \\
\hline Fiber Length (mm) & 0.8276 & 0.2239 & 3.6964 & 0.0344 & DFE=3 \\
\hline Volume Frac. (\%) & 0.101 & 0.2239 & 0.451 & 0.6826 & DFR=5 \\
\hline Fiber Length*Vol. Frac. & -0.013 & 0.0024 & -5.2926 & 0.0132 & SSR=145.49 \\
\hline Fiber Length^2 & -0.0061 & 0.0035 & -1.7679 & 0.1752 & F=7.5886 \\
\hline Volume Frac. ${ }^{\wedge 2}$ & 0.0038 & 0.0035 & 1.0868 & 0.3566 & $\begin{array}{l}\text { P-val } \\
=0.06296\end{array}$ \\
\hline & & & & & \\
\hline
\end{tabular}

Table 6. Analysis of variance for modulus of elasticity

\begin{tabular}{|lccccc|}
\hline Source & Sum Sq. & d. $f$. & Mean Sq. & F & Prob $>$ F \\
\hline X1 & 24.342 & 2 & 12.1709 & 0.41 & 0.689 \\
X2 & 13.74 & 2 & 6.8701 & 0.23 & 0.8036 \\
Brror & 118.914 & 4 & 29.7285 & & \\
Total & 156.996 & 8 & & & \\
& & & & & \\
& & & & &
\end{tabular}




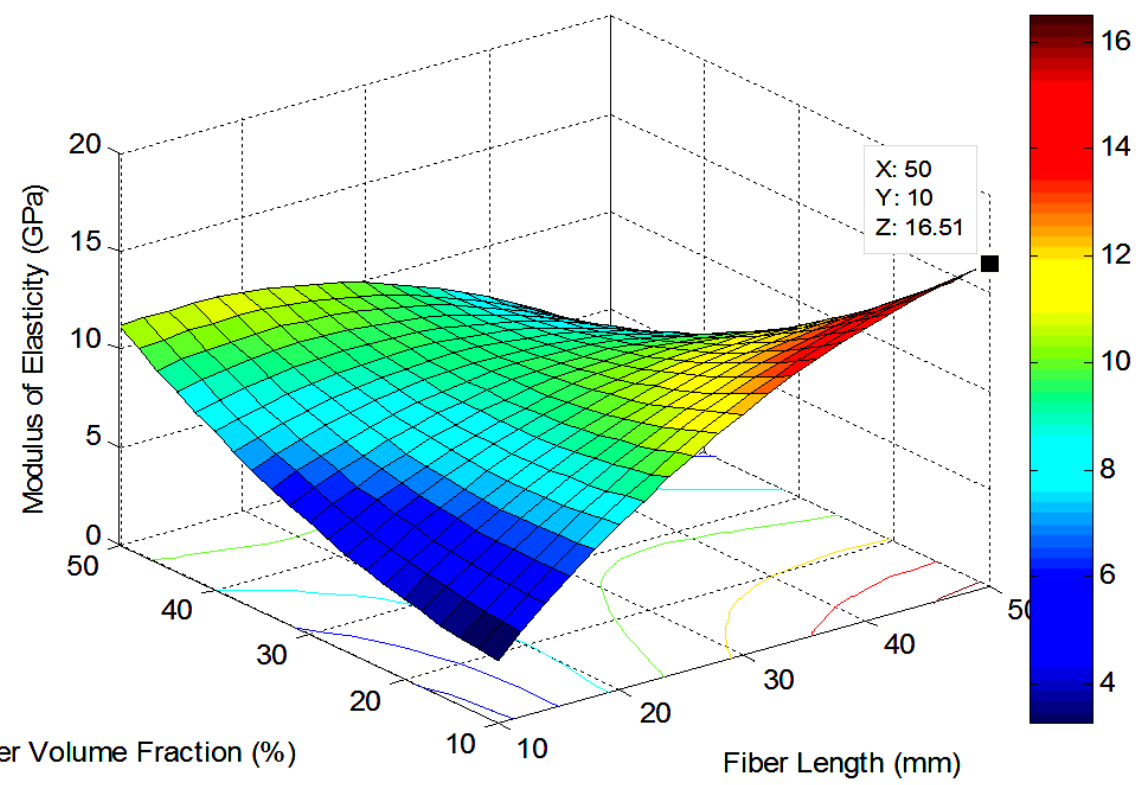

Figure 2. Surface plot and analysis of variance for modulus of elasticity (MOE).

Table 7. Response surface model table for toughness analysis.

\begin{tabular}{|l|l|l|l|l|l|}
\hline Variables & Coefficients & Std. Error & t-stat & P-value & F-stat \\
\hline Constant & -1.6107 & 3.2393 & -0.4973 & 0.6532 & SSE=6.7935 \\
\hline Fiber Length (mm) & 0.2527 & 0.1721 & 1.4687 & 0.2382 & DFE=3 \\
\hline Volume Frac. (\%) & -0.0676 & 0.1721 & -0.3931 & 0.7205 & DFR=5 \\
\hline Fiber Length*Vol. Frac. & -0.0022 & 0.0019 & -1.1957 & 0.3177 & SSR=9.2102 \\
\hline Fiber Length^2 & -0.0027 & 0.0027 & -1.0113 & 0.3864 & F=0.81345 \\
\hline Volume Frac.^2 & 0.0025 & 0.0027 & 0.9237 & 0.4238 & $\begin{array}{l}\text { P-val } \\
=0.60922\end{array}$ \\
\hline & & & & & \\
\hline
\end{tabular}

Table 8. Analysis of variance for toughness.

\begin{tabular}{|lccccc|}
\hline Source & Sum Sq. & d. f. & Mean Sq. & F & Prob $>$ F \\
\hline X1 & 3.6764 & 2 & 1.8382 & 0.73 & 0.5355 \\
X2 & 2.2964 & 2 & 1.14818 & 0.46 & 0.6621 \\
Brror & 10.031 & 4 & 2.50774 & & \\
Total & 16.0037 & 8 & & & \\
& & & & & \\
\end{tabular}




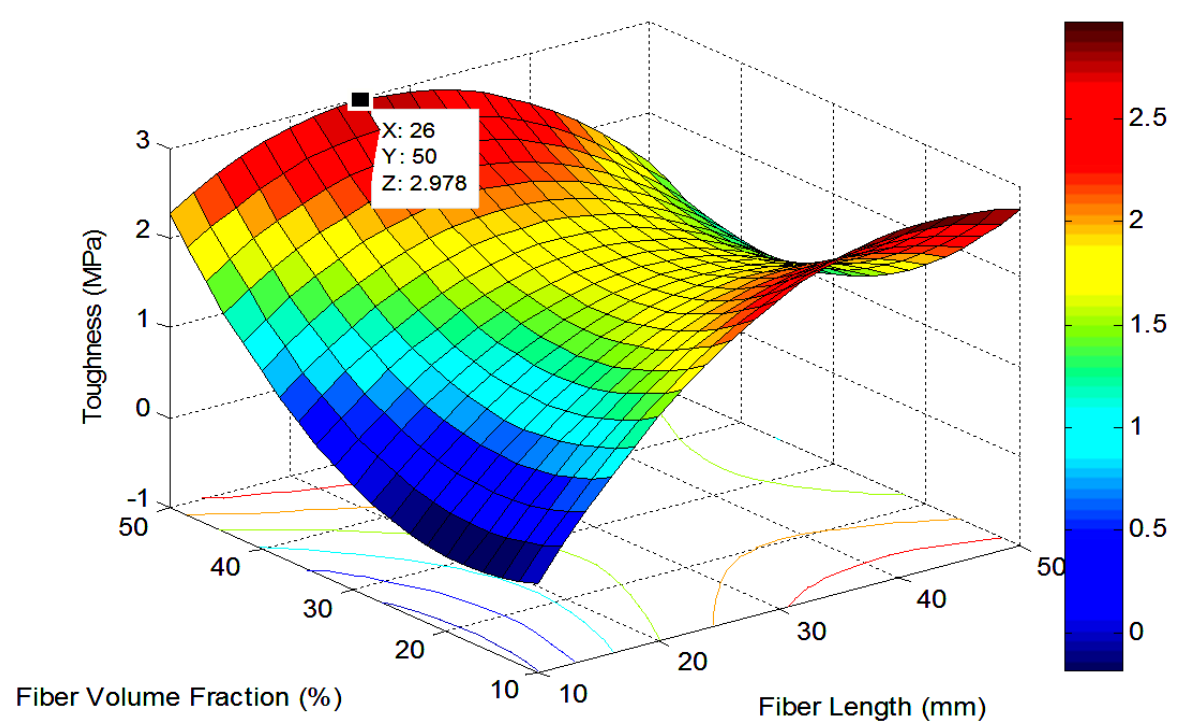

Figure 3. Surface plot and analysis of variance for toughness.

Table 9. Response surface model table for ultimate elongation analysis.

\begin{tabular}{|l|l|l|l|l|l|}
\hline Variables & Coefficients & Std. Error & t-stat & P-value & F-stat \\
\hline Constant & 1.396 & 2.6849 & 0.5199 & 0.6390 & SSE=4.6671 \\
\hline Fiber Length (mm) & 0.1383 & 0.1426 & 0.9694 & 0.4038 & DFE=3 \\
\hline Volume Frac. (\%) & -0.1148 & 0.1426 & -0.8046 & 0.4799 & DFR=5 \\
\hline Fiber Length*Vol. Frac. & -0.0009 & 0.0016 & -0.5612 & 0.6138 & SSR=3.5697 \\
\hline Fiber Length^2 & -0.0017 & 0.0022 & -0.7691 & 0.4978 & F=0.45892 \\
\hline Volume Frac.^2 & 0.0024 & 0.0022 & 1.0960 & 0.3532 & $\begin{array}{l}\text { P-val } \\
=0.79115\end{array}$ \\
\hline & & & & & \\
\hline
\end{tabular}

Table 10. Analysis of variance for ultimate elongation of fiber.

\begin{tabular}{|c|c|c|c|c|c|}
\hline Source & Sum Sq- & d. $f$. & Mean Sq. & $\mathbf{F}$ & Prob $>$ F \\
\hline--------1 & -------- & ---- & -------- & ---1 & ------- \\
\hline$\times 1$ & 1.17242 & 2 & 0.58621 & 0.45 & 0.6638 \\
\hline$\times 2$ & 1.90729 & 2 & 0.95364 & 0.74 & 0.5329 \\
\hline Exrox & 5.15711 & 4 & 1. 28928 & & \\
\hline Total & 8.23682 & 8 & & & \\
\hline
\end{tabular}




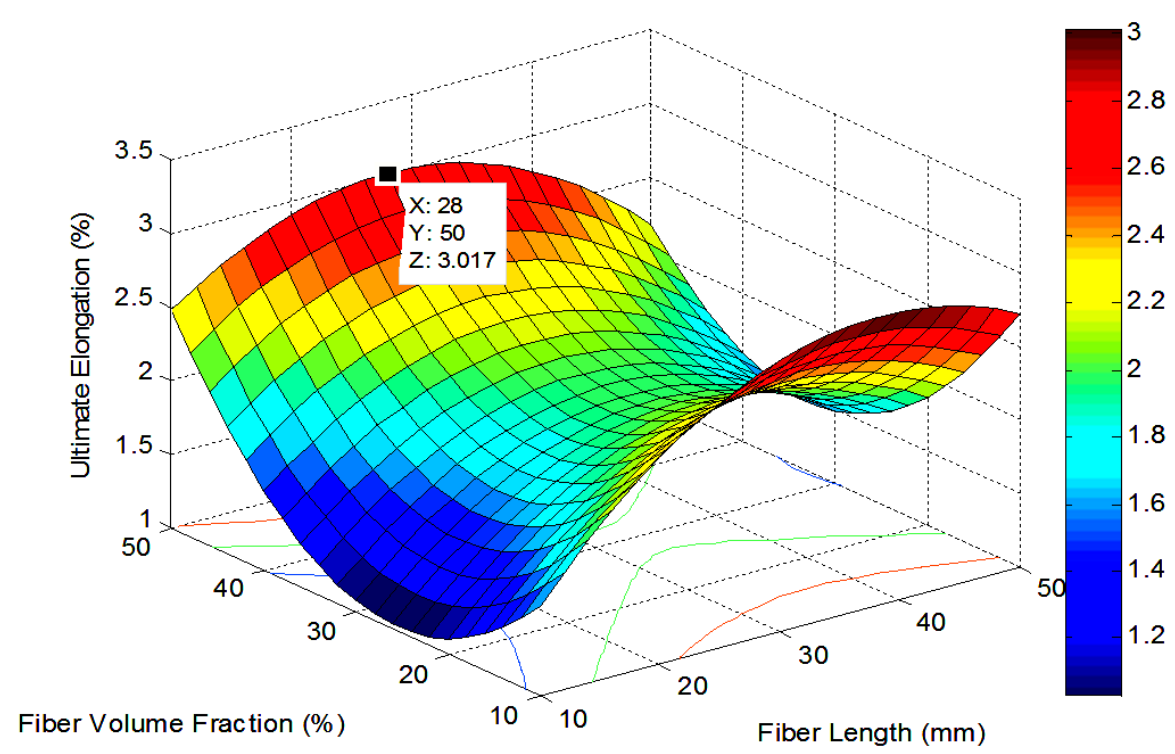

Figure 4. Surface plot and analysis of variance for ultimate elongation analysis.

Response surface methodology was used to analyze the influence of the variables viz.: fiber length and volume fraction on the mechanical properties of the Okra fiber reinforced polymer composite. Based on the value of the adjusted $R^{2}$ value the 'quadratic model' fits best for the analysis of the extent of variation/variability in the experiment. The model is stated below:

$$
Y(x)=C_{0}+C_{1} x_{1}+C_{2} X_{2}+C_{3} x_{1} x_{2}+C_{4} x_{1}^{2}+C_{5} x_{2}^{2}+\cdots+E .
$$

On application of the above stated model and from analysis using response surface methodology, according to Figure 1, tensile strength is highest at $\mathrm{Fl}=50 \mathrm{~mm}, \mathrm{Vf}=10 \%$. Ultimate tensile strength is $214 \mathrm{MPa}$ with ultimate elongation of $2.81 \mathrm{~mm}$. While virgin vinyl ester resin has an ultimate tensile strength in the range of $22-26 \mathrm{Mpa}$ and a mean value of $23.98 \mathrm{Mpa}$, after reinforcement using Okra fiber, there is significant improvement in the tensile strength. This is about $900 \%$ increment as compared to unreinforced vinyl ester. According to the tensile strength analysis Table $3, R^{2}$ which has value 0.9094 depicts that the model is accurate and can be said to explain up to $90 \%$ of observation in experimental data.

Also from Table 4, T-Stat value of fiber length and fiber length * vol. fraction is $\geq 2$. This shows that the two variables have significant effect on the tensile property of the 
composite. That is to say in varying the two parameters, the tensile strength of the composite can be improved or decreased.

The $\mathrm{P}$-value for fiber length and fiber volume fraction is 0.03 . This shows the model is adequate enough with above $90 \%$ confidence level and that the variables: fiber length, interaction between fiber length and volume fraction has significant influence on the tensile strength of the composite. The contour lines under the graph in Figure 1 are the region where the tensile strength is the same even though the fiber length and volume fraction may be changing.

Modulus of Elasticity: The analysis shows $R^{2}$ value of 0.9267 . This means that the model is accurate and explains $93 \%$ of observation in the experimental data as regards modulus of elasticity. The variables; fiber length and interaction between fiber length and volume fraction is significant as depicted by the T-stat values and P-values. According to the surface plot in Figure 2, the modulus of elasticity is highest at $\mathrm{Fl}=50$, $\mathrm{Vf}=10$. Modulus of Elasticity $=16.5$.

Toughness Analysis: As can be seen in Table 3, from T-stat and P-value, none of the parameters: $\mathrm{Fl}, \mathrm{Vf}$ and $\mathrm{Fl} * \mathrm{Vf}$ are significant and does not determine the toughness. This also explains poor $R^{2}$ value of 0.575 .

Elongation analysis from Table 9 changes in fiber length and volume fraction has no significant effect on the composite elongation hence low value of $R^{2}$ of 0.4334 .

\section{Conclusions}

The Okra fiber reinforced polymer composite has good tensile strength and this mechanical property can be affected by the fiber length of individual fiber used for each sample. The volume fraction of the fiber in the composite sample can also affect tensile strength of the composite.

The tensile strength of the composite increases linearly with fiber lengths up to $50 \mathrm{~mm}$ and volume fractions of $10 \%$. With ultimate tensile strength of $214 \mathrm{MPa}$, alternative to other raw materials for production of items that includes window blinds, desktops, automotive interiors etc. growing Okra plant and investing on its fiber extraction can also burst good employment opportunity. 


\section{References}

[1] I. M. De Rosa, J. M. Kenny, D. Pugliab, C. Santullic and F. Sarasinia, Morphological, thermal and mechanical characteristics of Okra (Abelmoschus esculentus) fibers as potential reinforcement in polymer composites, Composite Science and Technology 70(1) (2010), 116-122. https://doi.org/10.1016/j.compscitech.2009.09.013

[2] Feng Xing, Wei-wen Li, Fa-guang Leng and Yua Qi, Research and experiment on workability of concrete incorporated with cemfiber, Concrete 9 (2001), 54-58.

[3] K. Joseph, R. D. T. Filho, B. James, S. Thomas and L. H. de Carvalho, A review on sisal fiber reinforced polymer composites, Rev. Bras. Eng. Agríc. Ambient 3(3) (1999), 367379. https://doi.org/10.1590/1807-1929/agriambi.v3n3p367-379

[4] D. Khandal, P. Y. Mikus, P. Dole et al., Tailoring the properties of thermoplastic starch by blending with cinnamyl alcohol and radiation processing: an insight into the competitive grafting and scission reactions, Radiation Phys. Chem. 81(8) (2012), 986990. https://doi.org/10.1016/j.radphyschem.2011.10.028

[5] N. C. Kuchinda, W. B. Ndahi, S. T. O. Lagoke and M. K. Ahmed, The effect of nitrogen and period of weed interference on the fiber yield of kenaf (Hisbiscus cannabinus L.) in the northern Guinea Savana of Nigeria, Crop Protection 20(3) (2001), 229-235. https://doi.org/10.1016/S0261-2194(00)00138-1

[6] L. H. C. Mattoso, F. C. Ferreira and A. A. S. Curvelo, Sisal fiber: morphology and application in polymer composites, in: Lignocellulosic - Plastic Composites, A. L. Leão, F. X. Carvalho, E. Frollini, eds., Unesp publisher, Botucatu-São Paulo, Brazil, 1997, pp. 241-266.

[7] M. A. Martins and I. Joekes, Tire rubber-sisal composites: effect of mercerization and acetylation on reinforcement, Journal of Applied Polymer Science 89(9) (2003), 25072515. https://doi.org/10.1002/app.12285

[8] A. K. Mohanty, M. Misra and L. T. Drzal, Natural Fibers, Biopolymer and Biocomposites, Boca Raton: CRC Press, 2005. https://doi.org/10.1201/9780203508206

[9] D. Ray and B. K. Sarkar, Characterization of alkali - treated jute fibers for physical and mechanical properties, Journal of Applied Polymer Science 80(7) (2001), 1013-1020. https://doi.org/10.1002/app.1184 